\title{
Genetic analysis of emotional reactivity in sheep: effects of the genotypes of the lambs and of their dams
}

\author{
Alain BoISSY ${ }^{\mathrm{a} *}$, Jacques BoUIX ${ }^{\mathrm{b}}$, Pierre ORGEUR ${ }^{\mathrm{c}}$, \\ Pascal POINDRON ${ }^{c}$, Bernard BIBÉ ${ }^{b}$, Pierre LE NEINDRE ${ }^{\mathrm{a}}$ \\ ${ }^{a}$ Unité de Recherches sur les Herbivores ACS, INRA, \\ 63122 Saint-Genès Champanelle, France \\ ${ }^{\mathrm{b}}$ Station d'amélioration génétique des animaux, INRA, 31326 Castanet-Tolosan, France \\ ${ }^{\mathrm{c}}$ Physiologie de la Reproduction et des Comportements, UMR85 \\ INRA-CNRS-HN-University, 37380 Nouzilly, France
}

(Received 5 July 2004; accepted 24 March 2005)

\begin{abstract}
A total of 1347 weaned lambs from eight genotypes were tested over five consecutive years: Romanov (ROM) and Lacaune (LAC) pure breeds, the two F1 crossbreeds (RL and LR) and the offspring of ewes from these four genotypes sired with Berrichon-du-Cher rams (BCF). The lambs were individually exposed to three challenging tests involving novelty, human contact and social isolation. Ten synthetic variables were used to express social reactivity (i.e., active $v s$. passive strategy), exploratory activity and reactivity to humans. BCF crossbreds were more active (i.e., high bleats, locomotion and attempts to escape) than purebreds and F1. In contrast, ROM expressed more passive responses (i.e., low bleats and vigilance postures) than LAC and BCF crossbreds. In addition, ROM approached a motionless human less and had longer flight distances to an approaching human than did LAC and BCF crossbreds. When restrained, ROM, and to a lesser extent $\mathrm{B} \times \mathrm{ROM}$ and $\mathrm{B} \times \mathrm{LR}$, avoided human contact more than did LAC, RL and B $\times$ LAC. Most of these differences were explained by direct additive genetic effects while maternal influences or heterosis effects were rarely significant. The highest heritability was for high bleats $\left(h^{2}=0.48\right)$. Females were more active and avoided human contact more than did males.
\end{abstract}

genetics / emotional reactivity / human contact / social isolation / sheep

\section{INTRODUCTION}

Emotional reactivity defines the predisposition to express strong, quick and lasting emotions in response to external events [41]. Appropriate emotional

*Corresponding author: boissy@ clermont.inra.fr 
reactivity is important for animal welfare and production. For example in livestock, routine management procedures such as shearing, castration and transportation can trigger fear and anxiety $[21,22,48]$. Even if they generally require brief social isolation, they can be highly stressful for domestic ruminants [5] which are gregarious [7, 17]. Moreover, excessive fear may lead to the development of chronic stress and decreased productivity.

In Europe, handling is becoming progressively more stressful [28] because modern management tends to reduce the opportunities for animals to familiarise with humans. Reducing the frequency of potential aversive events or providing additional positive experiences to the animals, such as handling or training [24] may help to make the environment more suitable for livestock. It may also allow to adjust animal fearfulness, that is the propensity to experience fear or anxiety [3]. But the development of such environmental strategies is limited by the short time the farmers spend directly with their livestock, especially in extensive farming systems. Strengthening gregariousness may be another useful strategy for improving the ability of livestock to adapt to farming conditions [6]. Indeed social buffering influences the animal's ability to cope with its environment [33] and a higher flocking tendency facilitates routine flock management. Consequently, genetic selection aimed at reducing fearfulness and at strengthening gregariousness might be of economic and ethical significance for livestock production.

Heritability of emotional traits has been reported in laboratory species [36]. In farm species, domestication has changed traits related to production, such as muscle growth and milk yield, and also social grouping tendencies and fearfulness [35]. For instance, studies in sheep [26,37] and cattle [23,47] have shown that emotional reactivity differs between breeds. Nevertheless most studies on livestock concern reactivity to humans, whereas reactivity to novelty and to social isolation have not been accurately estimated [13, 19, 31, 46]. In addition breed differences can be partly explained by non-genetic influences such as maternal effects, as extensively documented in rodents [38]. Whereas nongenetic influences have received little attention in farm animal studies [9], recent results on sheep [14-16,39] have shown that the influence of prenatal experiences and postnatal maternal care should be carefully considered when estimating the genetic transmission of emotional traits.

The objective of the present study was to assess how flock tendency and the reactivity of lambs to novelty and to humans were influenced by their own genotype and by that of their dams, using eight genotypes of lambs from three breeds. 


\section{MATERIALS AND METHODS}

\subsection{Experimental animals and management}

The study was carried out at the INRA experimental farm of La Fage (South of France). Ewes were kept outside as a single flock (300 ewes/year) on rangeland throughout the year and during lambing (April). They grazed grass and shrubs all year around, received some roughages in the winter, and higher quality forage and some concentrate at the end of pregnancy. During the mating period (40 days), the ewes were assigned to three groups (100 ewes each) with only one sire breed (5 rams/year) per group. The sire of each lamb was not identified, but its breed was known. To prevent unequal numbers of progeny per sire, the rams were rotated daily (one ram/day). The lambs were weaned at 50 days of age, and were maintained as a single flock in a fenced parcel where they were fed ad libitum with hay and concentrate, and where they had minimal contact with humans until testing.

Data were collected on eight genotypes of male and female lambs $(n=639$ and 708, respectively) observed over a 5 year period (Tab. I). The basic design was a diallel cross between Romanov (ROM) and Lacaune (LAC) breeds, i.e. the two pure breeds and the two reciprocal crossbreds (RL and LR) from randomly chosen purebreds. Romanov is a prolific breed and is well known for its shy behaviour and high maternal qualities of the ewes. In the present study, the Lacaune sheep belonged to a meat line of this local breed selected for milk production in the Roquefort cheese industry and known for its ease of handling. Lambs $(B \times L A C, B \times R O M, B \times R L$, and $B \times L R)$ from the terminal cross between sires of the meat breed Berrichon-du-Cher (BCF) and ewes from the previous diallel experiment were included in the study [8] and completed the panel of the genotypes to be tested.

Genetic components of the lamb performances according to the genotype are described in Table II. Appropriate linear combinations of least-squares means were used to estimate differences between ROM and LAC (direct and maternal additive genetic effects, direct and maternal heterosis) and between the effects of BCF sires and ROM or LAC sires in purebred matings: [ $1 / 2$ (direct effects $\mathrm{BCF}-\mathrm{ROM})+$ direct heterosis $\mathrm{BCF} \times \mathrm{ROM}]$ and $[1 / 2$ (direct effects $\mathrm{BCF}-\mathrm{LAC})+$ direct heterosis $\mathrm{BCF} \times \mathrm{LAC}]$.

\subsection{Experimental setup and behavioural tests}

Every year, for ten consecutive days, the behavioural tests were performed two weeks after weaning under shelter and in a completely new environment. 
Table I. Experimental lambs according to the genotype and the year.

\begin{tabular}{|c|c|c|c|c|c|c|c|c|}
\hline \multicolumn{3}{|c|}{ Genotype } & \multicolumn{5}{|c|}{ Year } & \multirow[t]{2}{*}{ Total } \\
\hline Lamb & Sire & Dam & 1 & 2 & 3 & 4 & 5 & \\
\hline $\mathrm{ROM}^{1}$ & ROM & ROM & 34 & 24 & 30 & 27 & 27 & 142 \\
\hline $\mathrm{LAC}^{2}$ & LAC & LAC & 35 & 44 & 38 & 22 & 27 & 166 \\
\hline $\mathrm{RL}^{3}$ & ROM & LAC & 41 & 37 & 38 & 21 & 27 & 164 \\
\hline $\mathrm{LR}^{4}$ & LAC & ROM & 20 & 22 & 26 & 19 & 24 & 111 \\
\hline $\mathrm{B} \times \mathrm{ROM}^{6}$ & $\mathrm{BCF}^{5}$ & ROM & 24 & 14 & 18 & 21 & 31 & 108 \\
\hline $\mathrm{B} \times \mathrm{LAC}^{6}$ & $\mathrm{BCF}$ & LAC & 37 & 34 & 38 & 19 & 21 & 149 \\
\hline $\mathrm{B} \times \mathrm{RL}^{6}$ & $\mathrm{BCF}$ & $\mathrm{RL}$ & 44 & 60 & 57 & 82 & 65 & 308 \\
\hline $\mathrm{B} \times \mathrm{LR}^{6}$ & $\mathrm{BCF}$ & LR & 31 & 35 & 37 & 46 & 50 & 199 \\
\hline Total & & & 266 & 270 & 282 & 257 & 272 & 1347 \\
\hline
\end{tabular}

${ }^{1}$ ROM: Romanov breed

${ }^{2}$ LAC: Lacaune breed

${ }^{3} \mathrm{RL}: \mathrm{ROM} \times \mathrm{LAC}$ cross

${ }^{4}$ LR: LAC $\times$ ROM cross

${ }^{5} \mathrm{BCF}$ : Berrichon-du-Cher breed

${ }^{6} \mathrm{~B} \times$ : cross between a BCF sire and a ROM, LAC, RL or LR dam, respectively.

Table II. Relative genetic contributions to the performances of the eight lamb genotypes.

\begin{tabular}{|c|c|c|c|c|c|c|c|c|}
\hline \multirow[b]{2}{*}{ Genotype } & \multirow[b]{2}{*}{$\mu^{1}$} & \multicolumn{2}{|c|}{$\begin{array}{l}\text { Direct additive } \\
\text { genetic effect }\end{array}$} & \multicolumn{2}{|c|}{$\begin{array}{l}\text { Maternal additive } \\
\text { genetic effect }\end{array}$} & \multirow{2}{*}{$\begin{array}{l}\text { Direct maternal } \\
\text { heterosis effect } \\
\text { ROM } \times \text { LAC }\end{array}$} & \multicolumn{2}{|c|}{$\begin{array}{l}\text { Direct effect of } \\
\text { BCF sires }{ }^{2} \text { on: }\end{array}$} \\
\hline & & ROM & LAC & ROM & LAC & & $\begin{array}{l}\text { ROM } \\
\text { ewes }\end{array}$ & $\begin{array}{l}\text { LAC } \\
\text { ewes }\end{array}$ \\
\hline ROM & 1 & 1 & & 1 & & & & \\
\hline LAC & 1 & & 1 & & 1 & & & \\
\hline RL & 1 & $1 / 2$ & $1 / 2$ & & 1 & 1 & & \\
\hline LR & 1 & $1 / 2$ & $1 / 2$ & 1 & & 1 & & \\
\hline $\mathrm{B} \times \mathrm{ROM}$ & 1 & $1 / 2$ & & 1 & & & 1 & \\
\hline $\mathrm{B} \times \mathrm{LAC}$ & 1 & & $1 / 2$ & & 1 & & & 1 \\
\hline $\mathrm{B} \times \mathrm{RL}$ & 1 & $1 / 4$ & $1 / 4$ & $1 / 2$ & $1 / 2$ & 1 & $1 / 2$ & $1 / 2$ \\
\hline $\mathrm{B} \times \mathrm{LR}$ & 1 & $1 / 4$ & $1 / 4$ & $1 / 2$ & $1 / 2$ & 1 & $1 / 2$ & $1 / 2$ \\
\hline
\end{tabular}

${ }^{1} \mu$ : overall mean.

${ }^{2}$ Global direct effects of BCF terminal sires on ROM or LAC ewes: respectively [ $1 / 2$ direct effects $\mathrm{BCF}+$ direct heterosis $\mathrm{B} \times \mathrm{ROM})]$ or $\left[{ }^{1} / 2\right.$ direct effects $\mathrm{BCF}+$ direct heterosis $\left.\left.\mathrm{B} \times \mathrm{LAC}\right)\right]$. 
Thirty lambs were tested per day and chosen in such a way that the eight genotypes, sex, rearing type and age were balanced. On a given day, the lambs were individually exposed to three tests combining exposure to novelty, social separation and human contact with at least one hour and no more than three hours between two consecutive tests.

Two hours before the first test, the lambs to be tested were sorted from the main flock, placed in a sheltered waiting pen at $10 \mathrm{~m}$ from the testing pens. They remained in the waiting pen throughout the test day, except during the tests. Water was provided ad libitum in the waiting pen.

\subsubsection{Arena test}

This test evaluated the reactivity to social isolation and to a novel environment, and was conducted in an enclosure (Fig. 1) with a dirt floor surrounded by $2 \mathrm{~m}$ high solid walls. Six squares were plaster drawn on the floor. A bucket with concentrate was placed on square 2 . The lamb was left alone in the pen for $4 \mathrm{~min}$.

\subsubsection{Conflict test}

This test evaluated the result of two conflicting motivations: social attractiveness towards flock-mates and avoidance of a motionless human. The test pen was as above, but the bucket was removed and the wall adjacent to square 5 was replaced with a wire-mesh grid (Fig. 2). Three non-experimental flockmates were penned behind the grid. A human stood motionless in square 5 just in front of the grid. The lamb was left in the pen for $4 \mathrm{~min}$.

\subsubsection{Corridor test}

This test evaluated reactions to social isolation combined with repeated approaches by a human. It took place in a closed $0.6 \mathrm{~m}$ wide rectangular circuit with an outer $1.2 \mathrm{~m}$ high fence to prevent escape (Fig. 3). The inner fence was made of wire mesh. The circuit was virtually divided into six equal areas. First, the lamb was left alone for $30 \mathrm{~s}$ (isolation step). Next, a human entered the corridor and walked $(1 \mathrm{~m} / \mathrm{s})$ twice around in one minute (pursuit step). Every $5 \mathrm{~s}$, the observer recorded both areas where the human and the animal were located. Then, the human stood motionless in the corner of the corridor between areas 1 and 6 , and a second human entered the corridor and stood 


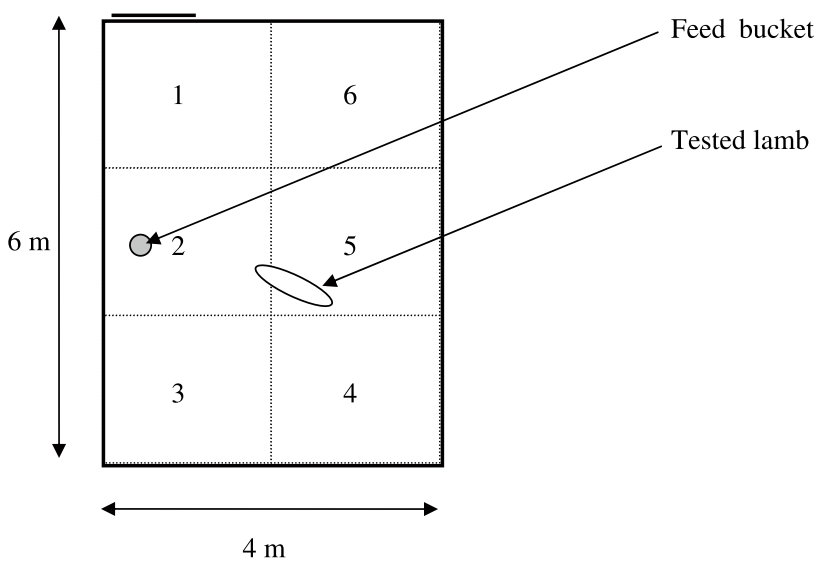

Figure 1. Experimental setup of the arena test for estimating the emotional reactivity of lambs to social isolation and novelty.

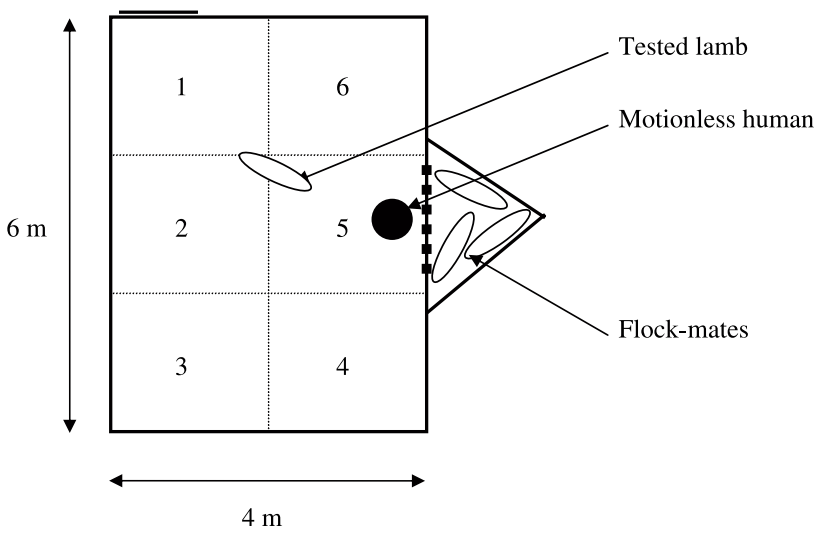

Figure 2. Experimental setup of the conflict test for evaluating the emotional reactivity of lambs to social attractiveness (towards familiar flock-mates) and to avoidance of a motionless human.

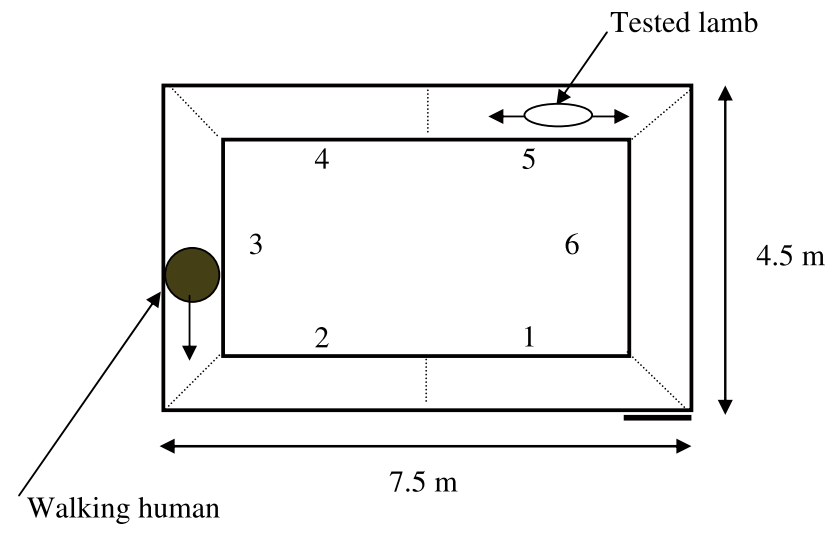

Figure 3. Experimental setup of the corridor test for estimating the emotional reactivity of lambs to an approaching human when the lamb is free to move (pursuit step), and when the lamb is restrained by a second motionless human (approach step). 
facing him at the corner between areas 2 and 3, in such a way that the animal was between the two humans. After $30 \mathrm{~s}$, the second human started to walk in order to push the lamb towards the stationary human. The approaching human stopped when the animal escaped by forcing the passage blocked by the stationary human (approach step). This last step was performed twice.

The two experimental tests involving human contact were complementary because they did not induce the same levels of stress. In the conflict test and in the pursuit step of the corridor test, the animal was free to approach or to avoid the human, and it coped with the event more easily [12] because he had control over the challenging event. None of the experimenters had any contact with the lambs prior to the experiment. One experimenter was located on a $2.5 \mathrm{~m}$ high platform to record the behavioural activities of the lambs by focal or scan sampling.

\subsection{Original measures}

Several behavioural measures were recorded during the tests (Tab. III). Measures were coded using a letter for each test: "A" for the arena test, "C" for the conflict test, and " $\mathrm{K}$ " for the corridor test. For corridor test measures, a number was added to indicate the step: " 1 " for the isolation step, " 2 " for the pursuit step, "3" for the first approach step, and "4" for the second approach step.

\subsection{Data analysis}

\subsubsection{Preliminary calculation}

Several raw measures were transformed using the square root transformation (Tab. IV) in order to minimise major deviation from the normal distribution. Some were divided into two or more classes. Frequencies of mictions, defecations and sniffing the walls, and duration of feeding had very low incidences and were excluded from further analyses.

Ten principal component analyses (PCA) were run using the PRINCOMP procedure in the SAS ${ }^{\circledR}$ package (version 8.1, SAS ${ }^{\circledR}$ Institute Inc., Cary, NC, USA). Each PCA was for a set of variables with a similar ethological significance. The first component of each PCA was defined as a synthetic variable. Three synthetic variables were specific to the reactivity to humans: the capacity to approach the motionless human in sight of flock-mates (HUMSOCIAL), and the tolerance towards being approached when the lamb was free to move (HUMAPPRO) or when it was partly restrained (HUMAVOID). High bleats 
Table III. Behavioural measures recorded in lambs individually exposed to the arena, conflict and corridor tests.

\begin{tabular}{|c|c|}
\hline ARENA TEST (4-min test) A- & Abbreviations \\
\hline Locomotion: number of squares entered $(n)$ & A-LOCO \\
\hline High bleat: number of times when the animal bleats mouth opened $(n)$ & A-HBLEAT \\
\hline Low bleat: number of times when the animal bleats mouth closed $(n)$ & A-LBLEAT \\
\hline Sniffing the floor or the walls $(n)$ & A-SNIFF \\
\hline $\begin{array}{l}\text { Vigilance: head in an upright position and ears perpendicular } \\
\text { to the head }(n)\end{array}$ & A-VIGIL \\
\hline Attempt to escape: jumping or rearing with two legs against the wall $(n)$ & A-ESCAP \\
\hline Defecation and urination & A-DEFEC \\
\hline Time near the bucket: time in the area $2(\mathrm{~s})$ & A-SQUAR2 \\
\hline Time of contact with the bucket (s) & A-SNIFB \\
\hline Time of feeding (s) & A-FEED \\
\hline CONFLICT TEST (4-min test) C- & \\
\hline Locomotion: number of squares entered $(n)$ & C-LOCO \\
\hline High bleat: mouth opened $(n)$ & C-HBLEAT \\
\hline Low bleat: mouth closed $(n)$ & C-LBLEAT \\
\hline Sniffing the floor or the walls $(n)$ & C-SNIFF \\
\hline $\begin{array}{l}\text { Vigilance: head in an upright position and ears perpendicular } \\
\text { to the head }(n)\end{array}$ & C-VIGIL \\
\hline Attempt to escape: jumping or rearing with two legs against the wall $(n)$ & C-ESCAP \\
\hline Defecation and urination & C-DEFEC \\
\hline $\begin{array}{l}\text { Time away from the flock-mates and human, i.e. time in the areas } 1,2 \\
\text { and } 3(\mathrm{~s})\end{array}$ & C-SQUAR123 \\
\hline Time near the flock-mates and human, i.e. time in the area $5(\mathrm{~s})$ & C-SQUAR5 \\
\hline Glance at the flock-mates at less than 2 metres $(n)$ & C-GLSOC1 \\
\hline Glance at the human at less than 2 metres $(n)$ & C-GLHUM1 \\
\hline Glance at the flock-mates at more than 2 metres $(n)$ & C-GLSOC2 \\
\hline Glance at the human at more than 2 metres $(n)$ & C-GLHUM2 \\
\hline Sniffing the grid: physical contact with flock-mates $(n)$ & C-SNIFSOC \\
\hline Sniffing or licking the human: physical contact with the human $(n)$ & C-SNIFHUM \\
\hline CORRIDOR TEST (3-min test) K- & \\
\hline Locomotion: number of squares entered in step $1(n)$ & K1-LOCO \\
\hline High bleat: mouth opened in steps 3 or $4(n)$ & K34-HBLEAT \\
\hline Low bleat: mouth closed in steps 3 or $4(n)$ & K34-LBLEAT \\
\hline Sniffing the floor or the walls in step $1(n)$ & K1-SNIFF \\
\hline Vigilance: head in an upright position in step $1(n)$ & K1-VIGIL \\
\hline $\begin{array}{l}\text { Attempt to escape: jumping or rearing with two legs against the wall in } \\
\text { step } 1(n)\end{array}$ & K1-ESCAP \\
\hline Defecation and urination in step 1 & K1-DEFEC \\
\hline Mean distance separating the human and the lamb in step $2(\mathrm{~m})$ & K2-PROX \\
\hline Time during which the human saw the lamb in step $2(\mathrm{~s})$ & K2-SEEN \\
\hline Flight distance in step $3(\mathrm{~m})$ & K3-FLIGHT \\
\hline Flight distance in step $4(\mathrm{~m})$ & K4-FLIGHT \\
\hline
\end{tabular}

$\mathrm{m}=$ metres, $n=$ number, $\mathrm{s}=$ seconds 
Table IV. Elementary statistics of the measures on weaned lambs exposed to the arena, conflict and corridor tests.

\begin{tabular}{|c|c|c|c|c|c|c|}
\hline Original measure & Unit(*) & Mean & SD & Mini & Maxi & Structure \\
\hline \multicolumn{7}{|l|}{ ARENA TEST } \\
\hline A-LOCO & $n$ & 35.9 & 14.6 & 3 & 80 & Continuous \\
\hline A-HBLEAT & $n$ & 43.9 & 21.7 & 0 & 172 & Continuous \\
\hline A-LBLEAT ${ }^{01}$ & $n$ & 0.88 & 0.33 & 0 & 1 & 2 classes \\
\hline A-SNIFF ${ }^{04}$ & $n$ & 1.91 & 1.17 & 0 & 4 & 5 classes \\
\hline A-VIGIL ${ }^{1 / 2}$ & $n$ & 2.56 & 1.32 & 0 & 6 & Continuous $^{1 / 2}$ \\
\hline A-ESCAP ${ }^{01}$ & $n$ & 0.39 & 0.49 & 0 & 1 & 2 classes \\
\hline A-SQUAR2 & s & 19.1 & 10.4 & 0 & 50 & Continuous \\
\hline A-SNIFB & $n$ & 3.10 & 1.91 & 0 & 12 & Continuous \\
\hline \multicolumn{7}{|c|}{ CONFLICT TEST } \\
\hline C-LOCO & $n$ & 19.7 & 11.8 & 0 & 70 & Continuous \\
\hline C-HBLEAT ${ }^{02}$ & $n$ & 1.05 & 0.69 & 0 & 2 & 3 classes \\
\hline C-LBLEAT ${ }^{01}$ & $n$ & 0.75 & 0.43 & 0 & 1 & 2 classes \\
\hline C-SNIFF ${ }^{03}$ & $n$ & 1.49 & 1.01 & 0 & 3 & 4 classes \\
\hline C-VIGIL ${ }^{02}$ & $n$ & 0.96 & 0.76 & 0 & 2 & 3 classes \\
\hline C-ESCAP ${ }^{01}$ & $n$ & 0.22 & 0.42 & 0 & 1 & 2 classes \\
\hline C-SQUAR123 $3^{1 / 2}$ & s & 5.43 & 2.37 & 0.5 & 10 & Continuous $^{1 / 2}$ \\
\hline C-SQUAR5 ${ }^{04}$ & $\mathrm{~s}$ & 2.03 & 1.26 & 0 & 4 & 5 classes \\
\hline C-GLSOC $1^{03}$ & $n$ & 1.47 & 1.03 & 0 & 3 & 4 classes \\
\hline C-GLHUM1 ${ }^{01}$ & $n$ & 0.66 & 0.48 & 0 & 1 & 2 classes \\
\hline C-GLSOC2 & $n$ & 15.6 & 8.8 & 0 & 51 & Continuous \\
\hline C-GLHUM2 $2^{1 / 2}$ & $n$ & 3.01 & 1.35 & 0 & 6.63 & Continuous $s^{1 / 2}$ \\
\hline C-SNIFSOC & $n$ & 6.65 & 5.33 & 0 & 25 & Continuous \\
\hline C-SNIFHUM $^{01}$ & $n$ & 0.28 & 0.45 & 0 & 1 & 2 classes \\
\hline \multicolumn{7}{|c|}{ CORRIDOR TEST } \\
\hline K1-LOCO & $n$ & 5.78 & 2.85 & 0 & 19 & Continuous \\
\hline K3-HBLEAT ${ }^{02}$ & $n$ & 0.95 & 0.78 & 0 & 2 & 3 classes \\
\hline K3-LBLEAT ${ }^{01}$ & $n$ & 0.17 & 0.38 & 0 & 1 & 2 classes \\
\hline K4-HBLEAT ${ }^{02}$ & $n$ & 0.98 & 0.76 & 0 & 2 & 3 classes \\
\hline K4-LBLEAT ${ }^{01}$ & $n$ & 0.16 & 0.37 & 0 & 1 & 2 classes \\
\hline K2-PROX & $n$ & 7.35 & 1.17 & 3.75 & 11.5 & Continuous \\
\hline K2-SEEN & s & 14.1 & 7.71 & 0 & 46 & Continuous \\
\hline K3-FLIGHT & $\mathrm{m}$ & 3.03 & 1.60 & 0 & 8 & Continuous \\
\hline K4-FLIGHT & $\mathrm{m}$ & 3.86 & 1.67 & 0 & 8 & Continuous \\
\hline
\end{tabular}

(*) units of the original measures: $\mathrm{m}=$ metres, $n=$ number, $\mathrm{s}=$ seconds

$1 / 2$ measures transformed by the square root of the original values.

01020304 measures ordinate in 2, 3, 4 or 5 classes, respectively. 
(HBLEAT), locomotion (LOCOM) and attempts to escape (ESCAP) expressed active reaction to isolation. On the contrary, low bleats (LBLEAT) and vigilance postures (VIGIL) characterised a passive strategy. Sniffing (SNIFFING) and proximity to the bucket (BUCKET) expressed exploration of the unfamiliar environment. The correlations between original measures and the 10 synthetic variables ranged between 0.48 and 0.92 (Tab. V). The synthetic variables accounted for $41 \%$ to $83 \%$ of the total variability.

\subsubsection{Analysis of the fixed effects}

Analyses of variance using the GLM procedure of the SAS ${ }^{\circledR}$ software package were performed on the synthetic variables using the following linear model:

$X_{i j k l m n}=\mu+y_{i}+a_{j}+y a_{i j}+s_{k}+n_{l}+s n_{k l}+g_{m}+b_{1 m} A_{k m}+b_{2 m} W_{k m}+E_{i j k l m n}$,

where $X_{i j k l m n}$ is the observation $n$ of lambs of genotype $m$, rearing type $l$, sex $k$ and age $j$ of the dam in year $i$ of experimentation; $\mu$ is the overall mean of the population; $y_{i}$ is the fixed effect of year $i ; a_{j}$ is the fixed effect of age $j$ of the dam; $y a_{i j}$ is the interaction between the year $i$ and the age $j$ of the dam; $s_{k}$ is the fixed effect of sex $k ; n_{l}$ is the fixed effect of rearing type $l ; s n_{k l}$ the interaction between sex $k$ and rearing type $l ; g_{m}$ is the fixed effect of genotype $m ; b_{1 m}$ is the coefficient of linear regression on the age (A) of animals of genotype $m$ and sex $k ; b_{2 m}$ is the corresponding coefficient on the live-weight (W) of genotype $m$ and sex $k ; E$ is the random residual error term. Linear combinations of the least-squares means for genotypes were obtained to evaluate between-breed genetic parameters.

Despite the lack of knowledge of the sire, an estimation of direct heritability was obtained using maternal filiations because the estimated maternal genetic and environmental variances were not different from zero (data not shown). Heritabilities were estimated with REML for an animal model, using VCE, with the same fixed effects as in the between-breed analysis.

\section{RESULTS}

\subsection{Analysis of the fixed effects}

The models explained between 6 and $28 \%$ of the total variance (Tab. VI). Genotype and year had significant effects on all 10 variables, but the latter was 
Table V. Definition of the synthetic variables and correlations with the original measures observed in weaned lambs exposed to the arena, conflict and corridor tests.

\begin{tabular}{|c|c|c|}
\hline $\begin{array}{c}\text { Synthetic } \\
\text { variable }(\%)\end{array}$ & Original measure & $\begin{array}{l}\text { Correlation between the } \\
\text { synthetic variable and the } \\
\text { original measure (r) }\end{array}$ \\
\hline \multirow{3}{*}{$\begin{array}{l}\text { LOCOM } \\
(52 \%)\end{array}$} & A-LOCO & 0.76 \\
\hline & $\mathrm{C}-\mathrm{LOCO}$ & 0.72 \\
\hline & K1-LOCO & 0.68 \\
\hline \multirow{4}{*}{$\begin{array}{l}\text { HBLEAT } \\
(62 \%)\end{array}$} & A-HBLEAT & 0.74 \\
\hline & C-HBLEAT ${ }^{02}$ & 0.72 \\
\hline & K3-HBLEAT ${ }^{02}$ & 0.86 \\
\hline & K4-HBLEAT ${ }^{02}$ & 0.83 \\
\hline \multirow{4}{*}{$\begin{array}{l}\text { LBLEAT } \\
(41 \%)\end{array}$} & A-LBLEAT $^{01}$ & 0.48 \\
\hline & C-LBLEAT ${ }^{01}$ & 0.50 \\
\hline & K3-LBLEAT ${ }^{01}$ & 0.76 \\
\hline & K4-LBLEAT ${ }^{01}$ & 0.76 \\
\hline \multirow{2}{*}{$\begin{array}{l}\text { SNIFFING } \\
(67 \%)\end{array}$} & A-SNIFF ${ }^{04}$ & 0.82 \\
\hline & C-SNIFF ${ }^{03}$ & 0.82 \\
\hline \multirow{2}{*}{$\begin{array}{l}\text { VIGIL } \\
(70 \%)\end{array}$} & A-VIGIL ${ }^{1 / 2}$ & 0.83 \\
\hline & C-VIGIL ${ }^{02}$ & 0.83 \\
\hline \multirow{2}{*}{$\begin{array}{l}\text { ESCAP } \\
(65 \%)\end{array}$} & A-ESCAP ${ }^{01}$ & 0.81 \\
\hline & C-ESCAP 01 & 0.81 \\
\hline \multirow{2}{*}{$\begin{array}{l}\text { BUCKET } \\
(68 \%)\end{array}$} & A-SQUAR2 & 0.82 \\
\hline & A-SNIFB & 0.82 \\
\hline \multirow{8}{*}{$\begin{array}{l}\text { HUMSOCIAL } \\
(57 \%)\end{array}$} & C-SQUAR123 $1 / 2$ & -0.80 \\
\hline & C-GLSOC2 & -0.76 \\
\hline & C-GLHUM2 $2^{1 / 2}$ & -0.68 \\
\hline & C-SQUAR5 ${ }^{04}$ & 0.92 \\
\hline & C-GLSOC $1^{03}$ & 0.87 \\
\hline & C-GLHUM1 $1^{01}$ & 0.78 \\
\hline & C-SNIFSOC & 0.59 \\
\hline & C-SNIFHUM ${ }^{01}$ & 0.61 \\
\hline \multirow{2}{*}{$\begin{array}{l}\text { HUMAPPRO } \\
(83 \%)\end{array}$} & K2-PROX & 0.91 \\
\hline & K2-SEEN & 0.91 \\
\hline \multirow{2}{*}{$\begin{array}{l}\text { HUMAVOID } \\
(74 \%)\end{array}$} & K3-FLIGHT & 0.86 \\
\hline & K4-FLIGHT & 0.86 \\
\hline
\end{tabular}

(\%) Percentage of the total variance of the original variables explained by the first component of PCA retained as synthetic variable.

01020304 measures ordinate in $2,3,4$ or 5 classes, respectively. 


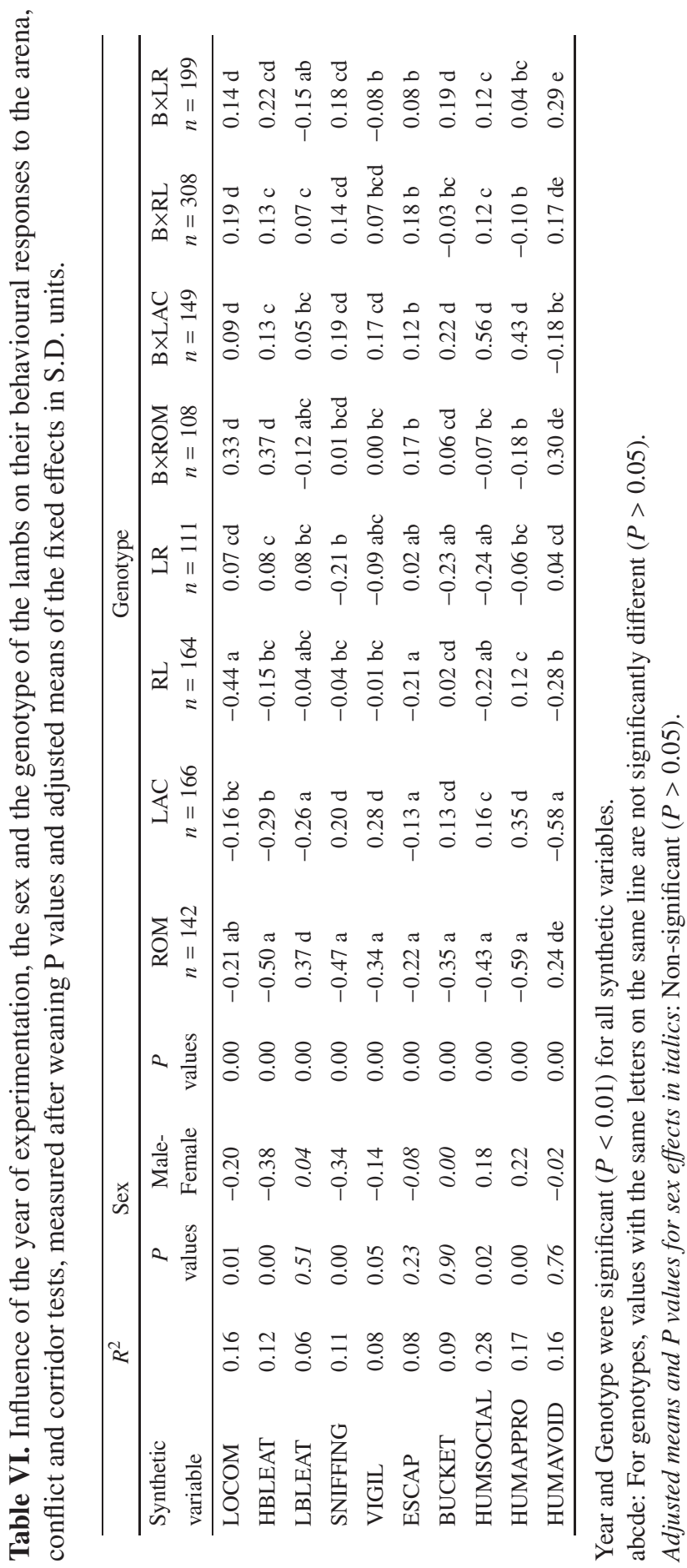


variable across the years. Sex had a significant effect on six variables. In contrast, the six other factors were mostly non-significant. Single lambs emitted less low bleats and attempted to escape more frequently than did twin lambs (LBLEAT: $P=0.02$; ESCAP: $P=0.01$ ). The heaviest lambs sniffed the floor more frequently (SNIFFING: $P=0.001$ ). The youngest lambs spent less time close to the human and their flock-mates in the conflict test (HUMSOCIAL: $P=0.001)$ and emitted more low bleats (LBLEAT: $P=0.04$ ).

\subsubsection{Sex differences}

Females were more active than males. They moved, attempted to escape, emitted high bleats and sniffed more frequently, and were more vigilant (LOCOM, ESCAP, HBLEAT, SNIFFING, VIGIL, respectively; Tab. VI). In addition, males spent more time near the motionless human in the conflict test (HUMSOCIAL) than females. They also had a higher proximity score and, conversely, a lower score for avoidance of the approaching human in the corridor test (HUMAPPRO and HUMAVOID).

\subsubsection{Differences between genotypes}

Genetic variability was highly significant for all the synthetic variables (Tab. VI). BCF crossbreds were the most active. They moved (LOCOM) more than the ROM or LAC pure breeds and RL crossbreeds; LR lambs had intermediate scores. Likewise, they emitted more high-bleats (HBLEAT) and attempted to escape (ESCAP) more frequently than the ROM, LAC and RL lambs, but RL lambs were not different from $B \times L A C, B \times R L$ and $B \times L R$ lambs for high-bleat frequencies. As for locomotion, the frequencies of high bleats and attempts to escape of the LR lambs were intermediate between BCF crossbreds and ROM or LAC purebreds.

ROM lambs approached the bucket (BUCKET) and sniffed the floor (SNIFFING) less frequently than the others, except for the LR lambs. In contrast, $\mathrm{LAC}$ and $\mathrm{B} \times \mathrm{LAC}$ and $\mathrm{B} \times \mathrm{LR}$ crossbreds explored the most. ROM were also less vigilant (VIGIL) than the others, except again for LR, whereas LAC were the most vigilant. ROM emitted low bleats (LBLEAT) far more frequently than the other lambs, whereas LAC produced less low bleats than the lambs of any other genotype.

In the presence of the flock-mates, the ROM did not approach the motionless human (HUMSOCIAL), in contrast to the $\mathrm{B} \times \mathrm{LAC}$ lambs and, to a lesser 
extent, the $\mathrm{LAC}$ and $\mathrm{B} \times \mathrm{RL}$ or $\mathrm{B} \times \mathrm{LR}$ lambs. Likewise, they did not tolerate being approached by the human (HUMAPPRO), whereas the B $\times$ LAC and LAC were the most easily approached. In restraint conditions, the flight distances in response to human approach (HUMAVOID) were the largest for the ROM, $\mathrm{B} \times \mathrm{ROM}, \mathrm{B} \times \mathrm{LR}$ and $\mathrm{B} \times \mathrm{RL}$ lambs. In contrast, the $\mathrm{LAC}$, and to a lesser extent the $\mathrm{RL}$ and $\mathrm{B} \times \mathrm{LAC}$ lambs, proved easiest to approach.

\subsection{Estimated between-breed genetic parameters}

Global genetic differences were essentially the consequence of the difference between the direct effects of ROM and LAC, and of the direct effects of terminal BCF sires on ROM or LAC ewes (Tab. VII). Heterosis had no significant influence, except for a maternal heterosis effect on flight distance (HUMAVOID) and for a direct heterosis effect on high bleats (HBLEAT). Maternal additive effects were only significant for locomotion (LOCOM), contact with the bucket (BUCKET) and flight distances (HUMAVOID). Locomotion and flight distance were higher with Romanov genes whereas contact with the bucket was mainly associated with Lacaune genes. There was clearly an opposite effect between the direct and maternal additive effects on locomotion.

\subsection{Estimates of within-breed genetic heritability}

Heritabilities estimated for the synthetic variables (Tab. VIII) varied between 14\% (ESCAPE) and 48\% (frequency of high bleats).

\section{DISCUSSION}

The highly contrasted behavioural reactions between the various genotypes provided valuable information on the emotional traits prevailing in each breed. However, very few maternal effects were found in our study.

Regarding the genetic effects, our results were in general agreement with observations reported in the literature for the Romanov breed. Regardless of the test considered, Romanov lambs exhibited the most passive responses, confirming the results of a previous report [26]. A high frequency of low bleats and weak level of exploration are indicators of behavioural inhibition due to mental discomfort triggered by novelty and social isolation $[37,44]$. The high degree of discomfort in the presence of humans found for Romanov lambs was also in agreement with the high fear reactions reported in Romanov ewes 
Genetics of emotivity in lambs

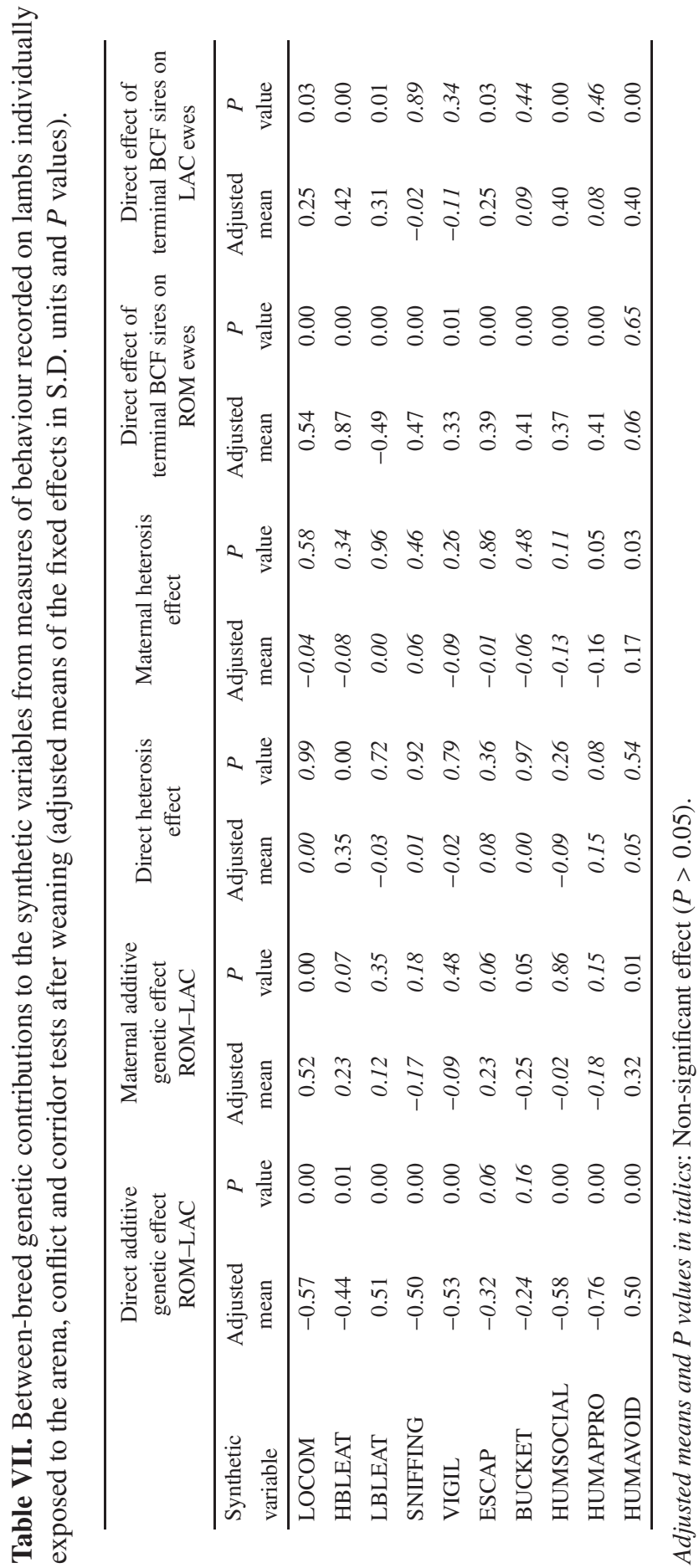


Table VIII. Preliminary estimation of the heritability for the synthetic variables obtained from measures of behaviour recorded on lambs individually exposed to the arena, conflict and corridor tests.

\begin{tabular}{lcc}
\hline Synthetic variable & $h^{2}$ & S.E. \\
\hline LOCOM & 0.34 & \pm 0.04 \\
HBLEAT & 0.48 & \pm 0.03 \\
LBLEAT & 0.28 & \pm 0.02 \\
SNIFFING & 0.36 & \pm 0.04 \\
VIGIL & 0.24 & \pm 0.02 \\
ESCAP & 0.14 & \pm 0.03 \\
BUCKET & 0.16 & \pm 0.04 \\
HUMSOCIAL & 0.32 & \pm 0.04 \\
HUMAPPRO & 0.23 & \pm 0.03 \\
HUMAVOID & 0.23 & \pm 0.03 \\
\hline
\end{tabular}

compared to the Merino breed [26] and in Romanov lambs compared with the Ile-de-France breed $[37,45]$. In contrast, BCF crossbred lambs were more active, exhibiting higher levels of locomotion and more high-pitched bleats and attempts to escape. Such behaviours are indicative of an active coping strategy, mainly translating a high social motivation $[4,5,37,44]$. The stronger flock tendency in BCF crossbred lambs would help them to better tolerate the contact with a motionless human in our conflict test. Lastly, Lacaune lambs were characterised by both a weak social reactivity and a high tolerance to humans.

The sex effects observed in our study suggested a stronger social tendency in female than in male lambs. In addition, it should be noted that ewes are more sensitive to novelty than males, and are more reluctant to approach a novel object [43]. Finally, females avoided human contact more frequently, despite their strong attraction to their flock-mates. This sex difference in the fear of humans has been previously reported in adult sheep $[43,45]$. Our results extend previous observations on adults or sub-adults to much younger animals.

Mother age, rearing type (single or twin), and lamb weight or age had little impact on the expression of their emotive traits. No particular explanation can be developed for the few significant effects encountered, which could reflect random fluctuations more than genuine biologically-significant factors.

Generally, total variation explained by the statistical analysis models was rather weak $\left(R^{2}=0.13(0.06-0.28)\right)$, despite the large size of the experiment. Repeating the tests might be a way to decrease residual variation since studies in other farm species have reported consistent individual reactions over time 
(goats: [30]; heifers: [25]). Anyway, our results revealed a predominance of direct additive genetic effects in the expression of differences between genotypes, whereas the weak maternal additive effects encountered suggested there was little non-genomic maternal transmission for the tests run after weaning. Direct additive genetic effects seem to exist both between and within breeds. We found moderate to high estimates of heritability, i.e. around $0.28(0.14-0.48)$. It should be noted that the highest estimates concern parameters that express active reactions induced by a disruption of the social environment. Crossvalidation of the reactivity to social isolation was obtained through the strong relationships between measures of either vocalisation or locomotion recorded in the three different tests. This confirms that we tested the same emotional trait, termed sociality.

Regarding reactivity towards humans, our estimate $\left(h^{2}=0.23\right)$ was in agreement with those found previously in dairy cattle [13, 40, 46], and beef cattle $[27,31]$. The heritability estimates found in the present study thus provide evidence in support of the possibility of selecting for emotional traits in sheep. This should improve their adaptability to most husbandry systems, and more particularly to the extensive conditions where selection to reduce fear of humans and improve sociality holds great potential for improving both animal welfare and efficiency of production. In addition, such breeding programmes would be facilitated by the existence of testing farms that have been established for several years, as is the case in France, designed to control young rams according to their zootechnical performances.

The lack of maternal effects in the present study is surprising. Social transmission of emotional traits across generations has been reported in mice and rats, especially through maternal care $[11,18]$. It is possible that the apparent absence of maternal effects in our study was related to the high degree of novelty imposed on the lambs under our testing conditions. Indeed, since lambs were reared outdoors, the experiences they acquired from their dams before weaning may have been of little use when confronted with the "artificial" conditions of indoor tests. The lack of maternal heterosis effects can be explained as the logical consequence of the weak additive maternal effects. Moreover, the lack of direct heterosis effects, at least between Romanov and Lacaune breeds, is more surprising, since it is well-known that heterosis effects in these breeds influence growth rate and survival [8].

The behavioural tests developed in our study appear to be well adapted for selecting subjects on the basis of emotional traits, but it will be necessary to gain a better knowledge of the variances and co-variances for these traits before they can be used for genetic improvement in practical breeding systems [8]. 
Selection for reduced fear or increased sociality might have a negative impact on desirable productivity traits, as observed with silver foxes selected for low fear of humans which have also changed in body shape and other traits [2]. On the contrary, selection for reducing fear responsiveness and/or increasing flock tendency might improve animal production and welfare. Ewes selected downwards for responsiveness to humans exhibit stronger maternal behaviour than their counterparts that have been selected upwards [32]. Likewise, a positive genetic correlation between docility to humans and maternal behaviour has been reported for Limousin cows [29].

Divergent selection on emotional reactivity might also help to develop an animal model for further analysis of the molecular and physiological interactions between genes and adaptive behaviours, starting with a quantitative trait loci (QTL) detection programme. Identification of QTL for emotional traits has previously been performed on laboratory animals [34], and was recently extended to the study of reactions to humans in cattle $[17,42]$.

This work has shown that it is possible to develop appropriate means of measuring emotional traits in young sheep and to effectively assess to what extent the observed differences are due to genetic effects. The importance of direct additive genetic effects on fearfulness and gregariousness was the major finding of the present study. This showed that further breeding programmes based on emotional traits could be undertaken to maintain or increase the adaptability of animals, more particularly in extensive farming, thereby to improve their welfare.

\section{ACKNOWLEDGEMENTS}

The authors are very grateful to the staff at the INRA experimental farm at la Fage (12) and in particular to D. Foulquié and R. Pailhores, who gave their support to the study by caring for the experimental flock. We are deeply indebted to all who contributed to collecting the field data: our colleagues S. Andanson and G. Trillat, and the students, M. Abreu Da Silva, G. Bouix, F. Gondret and C. Sarignac. We also thank Dr. C. Beaumont for her helpful advice on an earlier version, and Dr. C. Lee for English language revision of the manuscript.

\section{REFERENCES}

[1] Barbieri M.E., Manfredi E., Elsen J.M., Ricordeau G., Bouillon J., Grosclaude F., Mahé M.F., Bibé B., Influence du locus de la caséine Alpha s1 sur les performances laitières et les paramètres génétiques des chèvres de race Alpine, Genet. Sel. Evol. 27 (1998) 437-450. 
[2] Belyaev D.K., Destabilizing selection as a factor in domestication, J. Hered. 70 (1979) 301-308.

[3] Boissy A., Fear and fearfulness in determining behavior, in: Grandin T. (Ed.), Genetics and the Behavior of Domestic Animals, Academic Press, New York, USA, 1998, pp. 67-111.

[4] Boissy A., Bouissou M.F., Assessment of individual differences in behavioural reactions of heifers exposed to various fear-eliciting situations, Appl. Anim. Behav. Sci. 46 (1995) 17-31.

[5] Boissy A., Le Neindre P., Social influences on the reactivity of heifers: implications for learning abilities in operant conditioning, Appl. Anim. Behav. Sci. 25 (1990) 149-165.

[6] Boissy A., Nowak R., Orgeur P., Veissier I., Les liens sociaux chez les ruminants d'élevage : limites et moyens d'action pour favoriser l'intégration de l'animal dans son milieu, INRA Prod. Anim. 14 (2001) 79-90.

[7] Bouissou M.F., Boissy A., Le Neindre P., Veissier I., The social behaviour of cattle, in: Keeling L.J., Gonyou H.W. (Eds.), Social Behaviour in Farm Animals, CABI Publishing, Wallingford, UK, 2001, pp. 113-145.

[8] Bouix J., Jacquin M., Foulquié D., Autran P., Guillouet P., Hubert D., Bibé B., Genetic effects on sheep production in harsh environment and extensive management system, in: Proceedings of the 7th World Congress on Genetics Applied to Livestock Production, Vol. 29, Montpellier, France, 2002, pp. 441-448.

[9] Braastad B.O., Effects of prenatal stress on behaviour of offspring of laboratory and farmed mammals, Appl. Anim. Behav. Sci. 61 (1998) 159-180.

[10] Burrow H.M., Corbet N.J., Genetic and environmental factors affecting temperament of zebu and zebu-derived beef cattle grazed at pasture in the tropics, Aust. J. Agr. Res. 51 (2000) 155-162.

[11] Calatayud F., Coubard S., Belzung C., Emotional reactivity in mice may not be inherited but influenced by parents, Physiol. Behav. 80 (2004) 465-474.

[12] Desire L., Boissy A., Veissier I., Emotions in farm animals: a new approach to animal welfare in applied ethology, Behav. Process. 60 (2002) 165-180.

[13] Dickson D.P., Barr G.R., Johnson L.P., Wieckert D.A., Social dominance and temperament of Holstein cows, J. Dairy. Sci. 53 (1970) 904-907.

[14] Dwyer C.M., Lawrence A.B., Variability in the expression of maternal behaviour in primiparous sheep: effects of genotype and litter, Appl. Anim. Behav. Sci. 58 (1998) 311-330.

[15] Dwyer C.M., Lawrence A.B., Maternal behaviour in domestic sheep (Ovis aries): constancy and change with maternal experience, Behaviour 137 (2000) 1391-1413.

[16] Erhard H.W., Boissy A., Rae M.T., Rhind S.M., Effects of prenatal undernutrition on emotional reactivity and cognitive flexibility in adult sheep, Behav. Brain Res. 151 (2004) 25-35.

[17] Fisher A., Matthews L., The social behaviour of sheep, in: Keeling L.J., Gonyou H.W. (Eds.), Social Behaviour in Farm Animals, CAB International, Wallingford, UK, 2001, pp. 211-245. 
[18] Francis D., Diorio J., Liu D., Meaney M.J., Nongenomic transmission across generations of maternal behavior and stress responses in the rat, Science 286 (1999) 1155-1158.

[19] Grignard L., Boivin X., Boissy A., Le Neindre P., Do beef cattle react consistently to different handling situations, Appl. Anim. Behav. Sci. 71 (2001) 263-276.

[20] Hansen I., Christiansen F., Hansen H.-S., Braastad B., Bakken M., Variation in behavioural responses of ewes towards predator-related stimuli, Appl. Anim. Behav. Sci. 70 (2001) 227-237.

[21] Hargreaves A.L., Hutson G.D., The effect of gentling on heart rate, flight distance and aversion of sheep to a handling procedure, Appl. Anim. Behav. Sci. 26 (1990a) 243-252.

[22] Hargreaves A.L., Hutson G.D., Some effects of repeated handling on stress responses in sheep, Appl. Anim. Behav. Sci. 26 (1990b) 253-265.

[23] Hearnshaw H., Morris C.A., Genetic and environmental effects on a temperament score in beef cattle, Aust. J. Agr. Res. 35 (1984) 723-733.

[24] Hemsworth P.H., Coleman G.J., Human-Livestock Interactions: The stockperson and the productivity and welfare of intensively farmed animals, Hemsworth P.H. \& Coleman G. J., London, 1998.

[25] Kerr S.G.C., Wood-Gush D.G.M., The development of behaviour patterns and temperament in dairy heifers, Behav. Process. 15 (1987) 1-16.

[26] Le Neindre P., Poindron P., Trillat G., Orgeur P., Influence of breed on reactivity of sheep to humans, Genet. Sel. Evol. 25 (1993) 447-458.

[27] Le Neindre P., Trillat G., Sapa J., Ménissier F., Bonnet J.N., Chupin J.M., Individual differences in docility in Limousin cattle, J. Anim. Sci. 73 (1995) $1-5$.

[28] Le Neindre P., Murphy P.M., Boissy A., Purvis I.W., Orgeur P., Bouix J., Bibé B., Genetics of maternal ability in cattle and sheep, in: Proceedings of the 6th World Congress on Genetics Applied to Livestock Production 1998, Vol. 27, Armidale, Australia, pp. 23-30.

[29] Le Neindre P., Grignard L., Trillat G., Boissy A., Sapa F., Boivin X., Docile limousine cows are not poor mothers, in: Proceedings of the 7th World Congress on Genetics Applied to Livestock Production 2002, Montpellier, France, pp. 59-62.

[30] Lyons D.M., Price E.O., Moberg G.P., Individual differences in temperament of domestic dairy goats: constancy and change, Anim. Behav. 36 (1988) 1323-1333.

[31] Morris C.A., Cullen N.G., Kilgour R., Bremner K.J., Some genetic factors affecting temperament in Bos taurus cattle, New Zeal. J. Agr. Res. 37 (1994) 167-175.

[32] Murphy P.M., Lindsay D.R., Le Neindre P., Temperament of Merino ewes influences maternal behaviour and survival of lambs, in: Proceedings of the 32nd Congress of the International Society for Applied Ethology 1998, ClermontFerrand, France, 131.

[33] Nicol C.J., The social transmission of information and behaviour, Appl. Anim. Behav. Sci. 44 (1995) 79-98. 
[34] Plomin R., McClearn G.E., Gora-Maslak G., Neiderhiser M., Use of recombinant inbred strains to detect quantitative trait loci associated with behavior, Behav. Genet. 21 (1991) 99-116.

[35] Price E.O., Behavioral aspects of animal domestication, Q. Rev. Biol. 59 (1984) $1-39$.

[36] Ramos A., Mormède P., Stress and emotionality: a multidimensional and genetic approach, Neurosci. Biobehav. Rev. 22 (1998) 33-57.

[37] Romeyer A., Bouissou M.F., Assessment of fear reactions in domestic sheep and influence of breed and rearing conditions, Appl. Anim. Behav. Sci. 34 (1992) 93-119.

[38] Roubertoux P., Nosten-Bertrand M., Carlier M., Additive and interactive effects of genotype and maternal environment, Adv. Stud. Behav. 19 (1990) 205-247.

[39] Roussel S., Hemsworth P.H., Boissy A., Duvaux-Ponter C., Effects of repeated stress during pregnancy in ewes on the behavioural and physiological responses to stressful events and birth weight of their offspring, Appl. Anim. Behav. Sci. 85 (2004) 259-276.

[40] Sato S., Shiki H., Yamasaki F., The effects of early caressing on later tractability of calves, Jpn. J. Zootech. Sci. 55 (1984) 332-338.

[41] Savage R.D., Eysenck H.J., The definition and measurement of emotionality, in: Eysenck H.J. (Ed.), Experiments in Motivation, Pergamon Press, Oxford, 1964, pp. 292-314.

[42] Schmutz S.M., Stookey J.M., Winkelman-Sim D.C., Waltz C.S., Plante Y., Buchanan F.C., A QTL study of cattle behavioral traits in embryo transfer families, J. Hered. 92 (2001) 290-292.

[43] Vandenheede M., Bouissou M.F., Sex differences in fear reactions in sheep, Appl. Anim. Behav. Sci. 37 (1993) 39-55.

[44] Vandenheede M., Bouissou M.F., Picard M., Interpretation of behavioural reactions of sheep towards fear-eliciting situations, Appl. Anim. Behav. Sci. 58 (1998) 293-310.

[45] Vierin M., Bouissou M.F., Responses of weaned lambs to fear-eliciting situations: origin of individual differences, Dev. Psychobiol. 42 (2003) 131-147.

[46] Visscher P.M., Goddard M.E., Genetic parameters for milk yield, survival, workability, and type traits for Australian dairy cattle, J. Dairy Sci. 78 (1995) 205-220.

[47] Voisinet B.D., Grandin T., O'Connor S.F., Tatum J.D., Deesing M.J., Bos indicus-cross feedlot cattle with excitable temperaments have tougher meat and a higher incidence of borderline dark cutters, Meat. Sci. 46 (1997) 367-377.

[48] Wohlt J.E., Allyn M.E., Zajac P.K., Katz L.S., Cortisol increases in plasma of Holstein heifer calves from handling and method of electrical dehorning, J. Dairy Sci. 77 (1994) 3725-3729. 